\title{
The Impact of Technological Innovation on Corporate Performance: Evidence From the Communication and Cultural Industry in China
}

\author{
Maoguo $\mathrm{Wu}^{1} \& \mathrm{Nan} \mathrm{Gu}^{1}$ \\ ${ }^{1}$ SHU-UTS SILC Business School, Shanghai University, Shanghai, China \\ Correspondence: Maoguo Wu, SHU-UTS SILC Business School, Shanghai University, 20 Chengzhong Road, \\ Jiading District, Shanghai 201899, China.
}

Received: September 5, 2018

Accepted: September 17, $2018 \quad$ Online Published: October 10, 2018

doi:10.5430/ijfr.v9n4p78

URL: https://doi.org/10.5430/ijfr.v9n4p78

\begin{abstract}
China's communication and cultural industry is an emerging industry at the primary stage of its development. Nowadays, the public's increasing demand for cultural products, coupled with the strong support from the state and the government for the communication and cultural industry, have provided huge room for the development of this industry. However, some listed companies in the communication and cultural industry have not kept up with the constantly changing market and have not invested heavily in $R \& D$ and technological innovation, resulting in widespread product homogeneity and poor corporate performance. This paper empirically tests the impact of technological innovation on corporate performance of 56 listed companies from 2007 to 2016 in the communication and cultural industry. Along with variables that proxy technological innovation, variables that proxy solvency, profitability, operational capability, development capability, social responsibility, and shareholder indicators are included in the regression as explanatory variables. Empirical results show that technological innovation has a positive impact on the corporate performance of listed companies in the communication and cultural industry.
\end{abstract}

Keywords: communication and cultural industry, technological innovation, corporate performance, panel data

\section{Introduction}

In today's era of rapid technological advancement and rapid informatization, the status and role of culture have become more and more important in the evaluation of comprehensive national strength. Since China's reform and opening up, its social structure, industrial configuration, and economic structure have undergone a series of changes. In this period of rapid development and change, listed companies in the communication and cultural industry have served as the organizer of China's cultural propaganda and the maker of market culture products, mass media have thus naturally received ardent attention from the public as a result. Although long-term, national control has served to foil corporate performance in this industry, development has nevertheless been rapid in recent years. In 2014, the state issued a policy of supporting the communication and cultural industry as a new sustainable growth point for the Chinese economy. In 2015, it allocated nearly RMB 5 billion of funds in subsidies to companies in the communication and cultural industry or the development of relevant business projects. In addition, developing information technology also promotes the development of the communication and cultural industry. Hence, although this industry is in its infancy, under the dual stimulation of these policies and the economy, it is believed that all areas of the communication and cultural industry will continue to make progress and the upside potential is huge. With the changes of the times and the advancement of science and technology having huge implications on business, companies are bound to break through and innovate at the technical level to achieve competitive advantage. It is therefore imperative to study the impact of technological innovation on the corporate performance of listed companies in the communication and cultural industry.

The communication and cultural industry is an emerging industry with rapid development and great potential. Compared with traditional industries which have been comprehensively investigated, few studies have been conducted on the corporate performance of the communication and cultural industry. Besides, most existing literature only studies the impact of financial factors on corporate performance. Contributing to existing literature, this paper investigates the impact of non-financial factors on corporate performance, among which technological innovation is specifically examined. This paper selects 56 listed companies in the communication and cultural industry spanning from 2007 to 2016. Other factors that are closely related to the communication and cultural industry are also 
investigated. Variables that proxy solvency, profitability, operational capability, development capability, social responsibility, and shareholder indicators are all included in the regression as control variables. After preliminary tests, the fixed effect model that controls for heteroskedasticity is utilized for regression. Empirical results show that technological innovation has a positive impact on the corporate performance of listed companies in the communication and cultural industry.

The remaining part of this paper is organized as follows. Section 2 reviews the related literature. Section 3 introduces the data and presents the empirical analysis. Section 4 proposes policy implications and concludes the paper.

\section{Related Literature}

Regarding the definition and the measurement of the corporate performance of companies in the communication and cultural industry, the form and the structure of this industry in China is quite different from that of other countries. First of all, companies in the communication industry in China used to be mostly state-owned. Only until recently have those companies been gradually privatized. Listed companies in the communication industry have a relatively short history of operation. As a result, little research has been conducted on the communication and cultural industry so far. Liu and Cheng (2008) took Zhongshi Media as an example, and utilized the corporate performance assessment framework, including operational capability, profitability, and solvency to analyze the corporate performance of Zhongshi Media. Hanna et al. (2011) pointed out that with the transformation of the communication and cultural industry from traditional media to electronic media, new corporate performance evaluation methods, i.e., systematic analysis method, have become prevalent. Huang (2012) constructed a corporate performance assessment system for listed companies in the communication and cultural industry using the balanced scorecard, which includes financial capabilities, internal business processes, customer dimensions, and learning and growth. Empirical results found that financial capabilities and internal business processes were the two main influencing factors, while the other two were auxiliary assessment indicators, since the correlation is weak. Liu (2013) evaluated and comprehensively analyzed the corporate performance of listed companies in China's communication and cultural industry through factor analysis and DEA_Bootstrap. Empirical results found that the overall operating efficiency of the industry is low; from the perspective of the cultural segment, the performance of the two major start-up industries of animation and advertising are at the forefront, while the film, television, and communication industries are ranked lower. Yang and Chen (2013) used the gray correlation degree method and established an index evaluation system in the corporate performance evaluation system of listed companies in the communication and cultural industry.

Regarding the financial factors affecting corporate performance, Deng (2009) selected 12 listed companies in the Shanghai and Shenzhen Stock Exchange in 2008, and used principal component analysis and factor analysis to evaluate the corporate performance of the 12 listed companies. Financial factors are included in the regression for the assessment of their impact on corporate performance. The results found that these companies yield significantly different corporate performance outcomes, which may be due to differentiation of the main business income's contribution to total profit, or geographical advantage. Different conclusions were reached in previous studies on the impact of capital structure. Liu (2011) selected 18 companies in the communication and cultural industry and studied the relationship between capital structure and corporate performance. The study showed that the asset-liability ratio is negatively correlated with the return on equity (ROE) and that the optimal liability interval maximizes ROE. The study then concluded with the suggestion of expanding financing to improve corporate performance. Similarly, Yue (2012) investigated 14 companies in the communication and cultural industry listed on Shanghai and Shenzhen A-shares and overseas. Empirical results found that the asset-liability ratio is negatively correlated with corporate performance. However, Yan and Gao (2011) found that the asset-liability ratio has a positive impact on the corporate performance of companies in the communication and cultural industry ${ }^{[9]}$. For the publishing segment, previous literature mostly examines the impact of financial factors on corporate performance, and different results were found. Huang (2012) evaluated the corporate performance of 10 listed companies in the publishing segment. The study found that, first of all, from the perspective of each company and according to the four aspects of performance evaluation, the development of these 10 companies entails several advantages. Overall, the financial risk and profitability in performance evaluation are relatively stable. Moreover, from the perspective of the industry, the growth capability of the publishing segment is relatively good, but there is still a huge gap between the publishing segment and other segments in the industry in terms of profitability and operational capability. On the contrary, Wang and Xie (2013) evaluated the corporate performance of 10 listed companies in the publishing segment in 2012. They found that profitability yields improve in the stock market, while growth capability however does not feature good performance.

Regarding the non-financial factors affecting corporate performance, Gong (2010) found that the communication and 
cultural industry has positively promoted China's economic development. He also proposed that in order to help the communication and cultural industry to further develop, companies in this industry need to pay attention to the introduction and cultivation of talents in order to stay abreast of the rapid developments in technology. Yu and Pan (2013) hypothesized that the proportion of executives in a company is an important part of the corporate culture and is an intermediate force of the company, which, in turn, has a positive impact on the corporate performance of companies in the communication and cultural industry. The study examined the data of the executives of listed companies in the Shanghai and Shenzhen stock exchange from 2011 to 2012, and found that the average salary paid to senior executives and the background of the senior management team are two factors which have a positive effect on the corporate performance of companies in the communication and cultural industry. However, the management style of the senior management team has no significant impact on corporate performance. Sun and Chen (2013) used a non-balanced panel data set of listed companies from 2002 to 2011 in the communication and cultural industry, and studied the overall impact of mechanisms both internal and governmental, such as the relationship in ownership structure, executive incentives, and corporate performance. The results showed that executive incentives are positively significantly related to companies' corporate performance, while ownership structure is negatively significantly correlated with companies' corporate performance. Wang and Yang (2013) evaluated the technical efficiency of 27 companies in the communication and cultural industry from 2006 to 2010 based on stochastic frontier analysis (SFA). The results showed that the overall technical efficiency of the communication and cultural industry is still low, at 0.66 , but it is nevertheless on the rise. Liu et al. (2015) collected data on financial capabilities and the external institutional environment of listed companies in the communication and cultural industry from 2008 to 2013, and they studied the impact of governmental subsidies on companies' corporate performance. Empirical evidence showed that government subsidies are positively correlated with corporate performance, but they are not significant.

With the development of the times, the performance measurement system has undergone significant development by adding in more indicators. In terms of the measurement structure of financial capabilities, four factors, i.e., profitability, operational capability, solvency, and development capability form the basis of performance measurement. The balanced scorecard adds three other dimensions. Although the range of factors in the performance measurement system is broadened, the correlation of financial factors and non-financial factors is low, and the applicability of this evaluation is weak. Rather than using a single indicator, empirical analysis has also widely utilized comprehensive methods for evaluating corporate performance. Most of the evaluation methods using data envelopment analysis (DEA) are, however, for example, not accurate. Since the selection of input variables and output variables is subjective, no consistent technical efficiency can be calculated. Moreover, although the impact of financial factors like capital structure and non-financial factors like the proportion of technicians have been examined in previous research, few studies have included both financial factors and non-financial factors in the empirical analysis. In order to further explore the influencing factors of corporate performance by companies in the communication and cultural industry, this paper investigates the impact of both financial factors and non-financial factors, with a focus on technological innovation.

\section{Data and Empirical Analysis}

Based on stakeholder theory ${ }^{[17]}$ and principal-agent theory ${ }^{[18]}$, this paper selects 17 indicators which reflect financial capabilities (solvency, profitability, operational capability, development capability) and the non-financial aspects (technology innovation, social responsibility, shareholder indicators) of China's communication and cultural industry according to the characteristics of light assets and the emphasis on creative development. Four variables that proxy technological innovation and 13 other variables are empirically assessed. Variable description is summarized in Table 1 below.

Table 1. Variable description

\begin{tabular}{lll}
\hline & Variable and Denotation & Variable Meaning \\
\hline $\begin{array}{l}\text { Explained } \\
\text { Variable }\end{array}$ & Earnings Per Share & $\begin{array}{l}\text { Benefits that a company's common stock can } \\
\text { generate. Calculated as the ratio of the net } \\
\text { profit to the number of common shares at the } \\
\text { end of the year. }\end{array}$
\end{tabular}


Explanatory Variables

$\begin{array}{ll} & \begin{array}{l}\text { Proportion of Technicians } \\ (\mathrm{TECH})\end{array} \\ & \\ & \begin{array}{l}\text { Proportion of Staff with Co } \\ \text { Degrees } \\ \text { (COLL) }\end{array} \\ & \begin{array}{l}\text { R\&D Density } \\ \text { (RD) }\end{array} \\ \text { Current Liabilities Ratio } \\ \text { (CLR) } \\ \text { Aariables } & \begin{array}{l}\text { Asset Liabilities Ratio } \\ \text { (ALR) }\end{array} \\ & \begin{array}{l}\text { Profit Margin of Sales } \\ \text { (PMOS) }\end{array} \\ \text { Quick Ratio } \\ \text { (QUICKR) }\end{array}$

Total Asset Turnover (TURN)

Accounts Receivable Turnover (RECEI)

Inventory Turnover (STOCK)

Operating Income

Growth Rate

(OPERATEG)

Net Profit Growth Rate (PROG)
Intellectual property is particularly important in a company's intangible assets. Calculated as the ratio of intangible assets to total assets.

Developing products for customer needs is a necessary condition for promoting the development of the communication industry. Calculated as the ratio of the number of technicians to the total number of employees.

Innovation brought about by the introduction of talents has diversified the communication industry. Calculated as the ratio of the number of staff with college degrees to the total number of employees.

The ratio of total asset growth from one year to the total assets at the beginning of the year.

The ratio of current liabilities to total liabilities. The higher the ratio, the stronger the dependence on short-term funds.

The proportion of the total assets of listed companies through borrowing and financing. Calculated as the ratio of total assets to total liabilities.

Comparison between the net profit and sales through the sale of products.

The ratio of quick assets to current liabilities. The ability of liquidating current liabilities, which can be measured against the ability to repay short-term debt.

The ratio of net profit to average total assets for a certain period of time. It reflects the use of all assets by a company.

The turnover rate of accounts receivable and the management efficiency of a company. The higher the turnover rate, the faster the receipt of the account; on the contrary, it affects the solvency of a company. Calculated as the ratio of sales revenue to the average of accounts receivable.

The ratio of cost of goods sold to the average balance of stocks, the average balance of stocks $=$ (inventory at the beginning of the period + inventory at the end of the period) $/ 2$.

The change in a company's operating income in a year compared with the that of a previous year. The ratio of the change in operating income to the total operating income of the previous year.

Current net profit minus the net profit of the previous period, divided by the net profit of the previous period. The greater the value, the stronger the profitability of the company in the industry. 
Growth of Total Assets

(ASSG)

Government Subsidies

(GOV)

Income Tax (TAX)

Stock Concentration

(STOCKE)
The growth of a company's total assets in a period. Calculated as the ratio of total asset growth in a year to total assets at the beginning of the year.

The ratio of government subsidies to net profits. The greater the proportion, the more reliant is a company's net profit on the government.

The ratio of income tax to net profit.

A quantitative indicator that reflects whether or not the equity of a company is concentrated. Calculated as the ratio of the number of shares held by the largest shareholder to the total number of shares.

The data are gathered from the database WIND. By the end of 2016, there were a total of 60 listed companies in the communication and cultural industry in China. Four companies were excluded from the data set due to missing values. Hence, the data set consists of 56 listed companies from 2007 to 2016, giving a total observation of 560 . Descriptive statistics are shown in Table 2.

Table 2. Descriptive statistics

\begin{tabular}{lllll}
\hline Variable & Mean & Std. Dev. & Minimum & Maximum \\
\hline EPS & 0.33866 & 0.43679 & -1.37 & 2.91 \\
IAR & 4.33712 & 7.44232 & 0 & 79.336 \\
TECH & 18.27104 & 17.28846 & 1.8114 & 81.3793 \\
COLL & 33.27830 & 17.87220 & 2.29 & 78.32 \\
RD & 3.23475 & 3.40288 & 0.03 & 17.24 \\
CLR & 82.43165 & 36.46709 & 18.4821 & 100 \\
ALR & 31.12693 & 23.55973 & 1.4917 & 95.3326 \\
QUICKR & 2.26776 & 4.91742 & 0 & 53.1308 \\
PMOS & 10.57081 & 13.56275 & -99.7975 & 56.5656 \\
TURN & 0.55703 & 0.49193 & 0 & 4.6858 \\
RECEI & 6.59231 & 10.85493 & 0 & 90.2096 \\
STOCKER & 7.58739 & 14.60384 & 0 & 98.6563 \\
OPERATEG & 10.15687 & 29.99888 & -100 & 99.9106 \\
PROG & 11.21603 & 30.26324 & -97.8627 & 99.8105 \\
ASSG & 10.52521 & 23.76448 & -100 & 93.7247 \\
GOV & 7.54809 & 12.10894 & -16.8846 & 98.1109 \\
TAX & 11.83416 & 14.08641 & -4.1745 & 73.7610 \\
STOCKE & 22.92596 & 24.79104 & 0 & 99.5 \\
\hline
\end{tabular}

In terms of solvency, the current debt ratio is much higher than the asset-liability ratio, indicating that the liabilities of some listed companies in the communication and cultural industry are almost made up of current debt ratios. Regarding profitability, the overall value of earnings per share is low, and the dispersion is large and polarized. Some companies in the communication and cultural industry have suffered losses for a long time.

In terms of technological innovation, from the perspective of R\&D density, the current level R\&D of China's 
communication and cultural industry is on the rise. The average value of the proportion of staff with college degrees is $33.28 \%$, indicating that the overall reasonable quality of the staff.

Among other non-financial factors, the operational capability of companies in the communication and cultural industry is weak, as the overall asset management quality, cash flow turnover, and inventory turnover are all low. In terms of development capability, operating income growth rate, net profit growth rate, and total asset growth rate, these are all characterized by the huge gap between minimum value and maximum value, indicating that the future development potential of listed companies of different segments of China's communication and cultural industry is quite different, and the development prospects of some segments can become better. Regarding social responsibility, the maximum value of government subsidies as a net profit ratio is as high as $98 \%$. Furthermore, the average ratio of income tax to net profit is close to $10 \%$, implying that the communication and cultural industry is overly dependent on government subsidies, resulting in a high net profit. In terms of equity structure, the concentration of equity in China's communication and cultural industry has a high value close to $23 \%$.

The regression function, ideally, would be expressed in the following form:

$$
\begin{aligned}
\text { EPS } & =\alpha+\beta_{1} C L R+\beta_{2} \text { ALR }+\beta_{3} \text { PMOS }+\beta_{4} \text { QUICKR }+\beta_{5} \text { TURN }+\beta_{6} \text { RECEI } \\
& +\beta_{7} \text { STOCKR }+\beta_{8} \text { OPERATEG }+\beta_{9} \text { PROG }+\beta_{10} \text { ASSG }+\beta_{11} I A R+\beta_{12} \text { TECH } \\
& +\beta_{13} \text { COLL }+\beta_{14} R D+\beta_{15} \text { GOV }+\beta_{16} \text { TAX }+\beta_{17} \text { STOCKE }+\varepsilon,
\end{aligned}
$$

where $\alpha$ is the intercept, $\beta_{i}, \mathrm{i}(1,2, \ldots 17)$ is a coefficient parameter, and $\varepsilon$ is the error term.

In order to avoid spurious regression, the unit root test is first performed to test for stationarity. The variable explained, explanatory variables, and control variables are all found to be stationary. Meanwhile, the Breusch-Pagan test finds that the random effect model outperforms Ordinary Least Square (OLS), while the F test finds that the fixed effect model is more suitable for the data set than OLS. The Hausman test concludes that the fixed effect model works better than random effect model. However, the results of the cross-sectional correlation test and the heteroscedasticity test are combined to determine the final model. The Pesaran test, Friedman test, and Frees test all find that there to be no cross-sectional dependence. Then there's the Davidson-MacKinnon test which finds that all explanatory variables are exogenous. The Wald test detects significant heteroskedasticity. It follows then, that the fixed effect model that controls heteroskedasticity is selected as the regression method.

The regression results and robustness check are shown in Table 3. Regression 1 is OLS that controls heteroskedasticity. Regression 2 shows the panel correction error model (PCSE). Regression 3 is pooled OLS that controls heteroskedasticity. Regression 4 is an asymptotic fixed effect model that controls heteroscedasticity. Regression 5 is a fixed effect model that controls heteroskedasticity. To that extent, this paper interprets the result of

\begin{tabular}{|c|c|c|c|c|c|}
\hline \multicolumn{6}{|c|}{ Explained Variable: EPS and Control Variables } \\
\hline & Reg. 1 & Reg. 2 & Reg. 3 & Reg. 4 & Reg. 5 \\
\hline & Coefficient & Coefficient & Coefficient & Coefficient & Coefficient \\
\hline & (T-Value) & (T-Value) & (T-Value) & (T-Value) & (T-Value) \\
\hline \multirow{2}{*}{ CLR } & $-0.00433 * * *$ & $-0.00350 * * *$ & $-0.00433 * * *$ & $-0.00350 * * *$ & $-0.00433 * * *$ \\
\hline & $(-3.96)$ & $(-3.85)$ & $(-4.79)$ & $(-6.94)$ & $(-4.05)$ \\
\hline \multirow{2}{*}{ ALR } & -0.00184 & -0.00149 & $-0.00184 * *$ & -0.00149 & $-0.00184^{*}$ \\
\hline & $(-1.58)$ & $(-0.72)$ & $(-3.16)$ & $(-1.35)$ & $(-1.92)$ \\
\hline \multirow{2}{*}{ PMOS } & $0.00000949 * *$ & $0.00000952 * * *$ & $0.00000949 *$ & $0.00000952 * * *$ & $0.00000949 *$ \\
\hline & $(2.51)$ & $(3.85)$ & $(2.18)$ & $(4.26)$ & (1.81) \\
\hline \multirow{2}{*}{ QUICKR } & 0.00319 & $0.00561 * *$ & $0.00319 *$ & $0.00561 *$ & 0.00319 \\
\hline & (1.50) & $(2.68)$ & (1.98) & $(2.14)$ & (1.01) \\
\hline TURN & $0.325 * * *$ & $0.325 * * *$ & $0.325^{* * *}$ & $0.325 * * *$ & $0.325 * * *$ \\
\hline
\end{tabular}
Regression 5.

Table 3. Regression results and robustness check 


\begin{tabular}{|c|c|c|c|c|c|}
\hline & $(4.20)$ & $(3.21)$ & $(5.85)$ & $(4.56)$ & $(5.95)$ \\
\hline \multirow{2}{*}{ RECEI } & 0.000354 & 0.000267 & 0.000354 & 0.000267 & $0.000354 * *$ \\
\hline & $(1.32)$ & $(1.68)$ & $(1.10)$ & $(1.37)$ & $(2.43)$ \\
\hline \multirow{2}{*}{ STOCKR } & $0.0000853^{* * *}$ & $0.0000230 * *$ & $0.0000853^{*}$ & $0.0000230 * *$ & $0.0000853 * * *$ \\
\hline & $(2.92)$ & $(2.40)$ & $(2.15)$ & $(3.23)$ & $(2.85)$ \\
\hline \multirow{2}{*}{ OPERATEG } & $-0.0000292 * *$ & -0.0000123 & $-0.0000292 * * *$ & -0.0000123 & -0.0000292 \\
\hline & $(-2.48)$ & $(-0.87)$ & $(-3.27)$ & $(-1.00)$ & $(-1.35)$ \\
\hline \multirow{2}{*}{ PROG } & $0.000237^{*}$ & 0.000208 & 0.000237 & 0.000208 & $0.000237^{* * *}$ \\
\hline & $(1.86)$ & $(1.61)$ & $(1.58)$ & $(1.77)$ & $(4.36)$ \\
\hline \multirow{2}{*}{ ASSG } & $0.000102^{* *}$ & 0.0000505 & $0.000102^{* *}$ & $0.0000505^{*}$ & $0.000102^{*}$ \\
\hline & $(2.41)$ & $(0.86)$ & $(3.15)$ & $(2.04)$ & $(1.91)$ \\
\hline \multirow{2}{*}{ IAR } & 0.00245 & -0.00371 & 0.00245 & -0.00371 & 0.00245 \\
\hline & $(1.00)$ & $(-0.86)$ & $(1.33)$ & $(-1.69)$ & $(1.01)$ \\
\hline \multirow{2}{*}{ TECH } & $0.00266^{* *}$ & 0.0000823 & 0.00266 & 0.0000823 & $0.00266^{* *}$ \\
\hline & $(2.00)$ & $(0.06)$ & $(1.43)$ & $(0.03)$ & $(1.95)$ \\
\hline \multirow{2}{*}{ COLL } & $-0.00475^{* * *}$ & 0.00418 & $-0.00475^{* * *}$ & 0.00418 & $-0.00475^{* * *}$ \\
\hline & $(-3.55)$ & $(1.52)$ & $(-3.31)$ & $(1.60)$ & $(-3.55)$ \\
\hline \multirow{2}{*}{$\mathrm{RD}$} & $0.00176^{* * *}$ & -0.0143 & 0.00176 & -0.0143 & $0.00176^{* * *}$ \\
\hline & $(0.25)$ & $(-0.76)$ & $(0.42)$ & $(-1.19)$ & $(0.33)$ \\
\hline \multirow{2}{*}{ GOV } & $-0.000321^{*}$ & -0.000296 & -0.000321 & -0.000296 & $-0.000321^{*}$ \\
\hline & $(-1.84)$ & $(-1.64)$ & $(-1.77)$ & $(-1.78)$ & $(-1.93)$ \\
\hline \multirow{2}{*}{ TAX } & $-0.00563 * * *$ & $-0.00515^{* * *}$ & $-0.00563 * * *$ & $-0.00515 * *$ & $-0.00563 * *$ \\
\hline & $(-5.65)$ & $(-4.18)$ & $(-4.63)$ & $(-3.21)$ & $(-4.48)$ \\
\hline \multirow{2}{*}{ STOCKE } & $0.00247 * *$ & 0.00186 & $0.00247 * *$ & 0.00186 & $0.00247 * * *$ \\
\hline & (2.49) & $(0.40)$ & $(2.73)$ & $(0.90)$ & (3.08) \\
\hline \multirow{2}{*}{ _CONS } & $0.633 * * *$ & 0.418 & $0.633^{* * *}$ & $0.418^{* *}$ & $0.633 * * *$ \\
\hline & $(5.73)$ & (1.62) & $(5.82)$ & $(2.72)$ & $(5.72)$ \\
\hline $\mathrm{N}$ & 270 & 270 & 270 & 270 & 270 \\
\hline
\end{tabular}

Note: $* * * * *, *$ denotes significant at $1 \%, 5 \%, 10 \%$ significance level, respectively.

It can be seen from the regression results that a positive correlation exists between the intangible asset ratio and EPS, but it is however not significant. Companies in the communication and cultural industry have high-quality intellectual property rights that have little effect on improving profitability. They also need to use this value to create sustainable wealth. Besides, a positive correlation exists between the proportion of technicians and EPS, and it is significant at a significance level of 5\%. The communication and cultural industry requires continuous promotion of creativity in order to use existing intellectual property to create more and more wealth. Listed companies should pay attention to the cultivation of professionals because they can create value. Moreover, a negative correlation exists between the proportion of staff with college degrees and EPS, and it is significant at a significance level of $1 \%$. The reason for this negative relationship is that the demand for products in the communication and cultural industry has gradually increased in recent years. As a result, companies have needed to hire more staff to sell products, and most sales staff have college degrees, which is a human resource misallocation, resulting in a negative impact on corporate performance. Furthermore, a positive correlation is observable between R\&D density and EPS, and its level of significance stands at $1 \%$. Companies in the communication and cultural industry are actively investing in R\&D, improving R\&D capabilities, and developing products that satisfy customers' ever-changing preferences. All of these can be beneficial to companies. 
In general, the positive impact of technological innovation on the corporate performance of companies in the communication and cultural industry is greater than the negative impact. Companies in the communication and cultural industry need to improve their R\&D capabilities, upgrade their technological level, develop products that fulfill customers' needs to gain a competitive advantage, and all the while create a constant source of value and wealth. In addition, it is imperative to pay attention to the optimization of human resources so as to enable the existing high-quality human resources to create more value for higher corporate performance.

The current asset ratio is negatively related with EPS, and its level of significance stands at $1 \%$. It shows that in China, the current debt ratio of listed companies in the communication and cultural industry is indeed high, and companies' excessive dependence on short-term liabilities for their operation leads to an unreasonable overall capital structure. The asset-liability ratio is also negatively related with EPS, with a significance level of $10 \%$. In the communication and cultural industry, the irrational capital structure caused by the high liquidity ratio also makes the asset-liability ratio have a certain negative impact on the profitability of companies. If it is in an economically unfavorable market environment, companies are prone to the problem of capital turnover. A net profit margin has a positive impact on EPS, with a significance level of $10 \%$. This indicates that companies should pay attention to the change of net profit every time they increase their sales income, and effectively improve the profitability of companies to a certain extent. The quick ratio is positively correlated with EPS, but not significant. It is necessary to combine the current asset ratio and the asset-liability ratio to reflect the solvency of listed companies in the communication and cultural industry.

In terms of operational capabilities, a positive correlation exists between the total asset turnover rate and EPS, with a significance level of $1 \%$. Companies in the communication and cultural industry can find out the weakness of their own assets through the analysis of this index, so that they can actively improve their efforts and improve utilization. The accounts receivable turnover rate is positively related with EPS, with a significance of 5\%. Inventory turnover is also positively related with EPS, with a significance of $1 \%$. It shows that a company can further improve its operational capability by increasing or improving its inventory turnover to increase its liquidity.

Among financial factors, operating income (year-on-year growth rate) is positively correlated with EPS, but not significant. Net profit (year-on-year growth rate), furthermore, is positively correlated with EPS, and it has a significance of $1 \%$. Companies in the communication and cultural industry can effectively understand their development and growth capabilities through the analysis of net profit, and also increase their profitability at the stage of strong growth. The variable total assets (year-on-year growth rate) are positively correlated with EPS, with a significance of $10 \%$.

Meanwhile, a negative correlation exists between government subsidies as a percentage of net profit and EPS, standing at $10 \%$. Companies in the communication and cultural industry, to a certain extent, rely on a portion of their profits, because of government subsidies, which have a negative social impact. Income tax as a percentage of net profit is also found to be negatively related with EPS, with a significance level of 5\%. It shows that government tax subsidies also cause a certain negative influence on company turnover. This, however, is because companies make use of government subsidies to falsify financial statements, so that their real profits are questioned. Stock concentration and EPS are positively related (significant at $1 \%$ significance level). It shows that the current shareholding structure of the communication and cultural industry enables shareholders to make reasonable and non-one-sided decisions that have a positive impact on listed companies.

\section{Conclusion and Policy Implications}

This paper investigates the impact of technological innovation on the corporate performance of companies in the communication and cultural industry. Utilizing a data set of 56 listed companies in the communication and cultural industry spanning from 2007 to 2016, both financial factors and non-financial factors are included in the regression. This paper controls financial factors (solvency, profitability, operational capability, development capability) and non-financial factors (social responsibility and shareholder indicators) for the purpose of examining the relationship between technological innovation and corporate performance. The following conclusions can be reached.

First of all, technological innovation, in general, is found to have a positive impact on the corporate performance of listed companies in China's communication and cultural industry. In terms of intangible assets and human resources, companies need to skillfully use technological innovation combined with intellectual property rights and optimal employment and allocation of human resources to gain a competitive advantage, create continuous value and wealth, and improve corporate performance. $R \& D$ is very important for the future development of the communication and cultural industry. Consumers' demand for communication and cultural products is no longer satisfied by traditional media such as newspapers, magazines, and broadcasts. It follows then that companies should increase R\&D and 
develop information media. Updating traditional communication and cultural products is the inevitable path for the future development of companies in the communication and cultural industry. Apart from that, they need to develop appropriate development plans for their own conditions, design unique and attractive cultural products, and thus enhance corporate value. Other factors such as solvency, profitability, operational capability, development capability, ownership structure, and social responsibility are all important factors influencing the corporate performance of companies in the communication and cultural industry.

Based on the above conclusions, the following policy implications are proposed.

Given the significant positive correlation between EPS and R\&D density and proportion of technicians, companies in the communication and cultural industry should invest more in the development of products within their capabilities. At this stage, the level of $R \& D$ investment in China's communication and cultural industry is not satisfactory. The tendency toward homogenization of communication and cultural products is a serious one and the industry as a whole lacks creativity, which leads to companies lacking their own distinct advantages. Companies in the communication and cultural industry should pursue the development of current technology, use virtual reality, digital networks and other emerging technologies to upgrade their original traditional business, create original and distinctive cultural products, and stimulate consumers' desire to consume. In addition, they also need to focus on professionalism and improve the training of personnel. Effective recruitment, retention, and incentive mechanisms can promote the creative ability of companies so that they can keep up with the pace of the times, and create a continuous and sustainable flow of wealth from existing intellectual property.

Given that solvency, operational capability, development capability, ownership structure and social responsibility are all important factors influencing the corporate performance of companies in the communication and cultural industry, they should rationalize the reduction of the current debt ratio and increase the proportion of long-term liabilities to achieve the aim of optimizing the capital structure, reducing the instability of funding sources, avoiding the increase of financial risks, and stabilizing the solvency and operational capacity. They can also open up other market channels and obtain new potential projects which can improve their development capabilities and profitability. In addition, companies in the communication and cultural industry can establish a diversified and balanced equity structure or establish a shareholder supervisory organization. This is done so as to optimize the adjustment of the shareholding structure in the development process, and effectively avoid having the largest shareholder solely holding a large proportion. With the strong support from the government, companies in the communication and cultural industry tend to have abundant funds. If the allocated subsidies are effectively and rationally utilized, more value can be created both for society and for companies' own well-being, rather than being used for falsification. Similarly, whilst remaining socially constrained, companies themselves must establish a sound management system and build up a foundation for sustainable development.

\section{References}

Chen, S., Li, J., \& Gong, F. (2010). An Empirical Analysis of the Impact of Development in the Cultural Industry on Regional Economic Growth (in Chinese). Economic Management, 31(6), 98-101.

Deng, J. (2009). Empirical Evaluation of the Corporate Performance of Listed Companies in China's Communication and Cultural Industry (in Chinese). Modern Trade Industry, (13), 86-87.

Hanna, R., et al. (2011). We're All Connected: The Power of the Social Media Environment. Business Horizons, (54), 265-273. https://doi.org/10.1016/j.bushor.2011.01.007

Hao, Y., \& Wu, B. (2009). Three-dimensional Structure and Basic Principles of Corporate Performance Evaluation from the Perspective of Stakeholders (in Chinese). Journal of Zhejiang Gongshang University, (2), 82-86.

Huang, X. (2012). The "Digital" Perspective of Listed Companies in the Publishing Segment - Operating Performance Analysis and Travel Report of The Publishing Listed Companies in China (in Chinese). View on Publishing, (5), 18-21.

Huang, X., \& Zhan, S. (2012). Construction of the Cultural Industry Performance Evaluation Index System (in Chinese). Statistics and Decision, (19), 41-43.

Li, J. (2011). Theory and Research Methods of Enterprise Performance Evaluation (in Chinese). Journal of Yanshan University.

Liu, L. (2013). Corporate Performance of Listed Companies in China's Cultural Industry - A Factor Analysis and DEA “Bootstrap Approach" (in Chinese). Times Finance, (9), 196-198. 
Liu, P., Zhao, L., \& Du, X. (2015). Performance Evaluation and Influencing Factors of Financial Subsidies on the Cultural Industry - Evidence from Listed Companies in China (in Chinese). Journal of Ocean University of China (Social Science Edition), (3), 55-60.

Liu, Y., Wang, C., \& Li, G. (2011). An Empirical Analysis of Capital Structure and Corporate Performance of Listed Companies in the Cultural Industry (in Chinese). Value Engineering, 30(36), 1-4.

Liu, Z., \& Cheng, J. (2008). Evaluation and Analysis of the Corporate Performance of Listed Media Companies Illustrated by the Case of Zhongshi Media (in Chinese). Commercial Marketing, (4), 44-46.

Pan, A., \& Yu, M. (2013). An Empirical Study on the Relationship between Executive Team Characteristics and Corporate Performance of Companies in the Cultural Industry (in Chinese). Guangdong Social Sciences, (5), 5-14.

Sun, W., \& Chen, J. (2013). Correlation between Internal Governance Mechanisms and Corporate Performance - An Empirical Study Based on Listed Companies in the Communication and Cultural Industry in China (in Chinese). Macroeconomic Research, (2), 80-90.

Wang, J., \& Yang, T. (2013). An Empirical Study on the Technical Efficiency of Listed Companies in China's Cultural Industry and Influencing Factors (in Chinese). Journal of Tianjin University of Commerce, 33(4), 3-9.

Wang, W., \& Xie, M. (2013). An Empirical Analysis of the Corporate Performance of Listed Companies in the Publishing Segment (in Chinese). Publishing Research, (1), 18-22.

Yan, C., \& Gao, G. (2011). An Empirical Study on the Corporate Performance and Capital Structure of Listed Companies in China's Cultural Industry (in Chinese). Oriental Corporate Culture, (4), 260-261.

Yang, X., \& Chen, L. (2013). Performance Evaluation of China's Listed Companies in the Cultural Industry Based on Grey Correlation Degree (in Chinese). Corporate Report, (22), 33-34.

Yue, T. (2012). Corporate Performance and Capital Structure of Listed Companies in Chinese Cultural Media - An Empirical Study Based on A-Shares and Overseas Listed Media Companies in 2005-2010 (in Chinese). Journal of Capital University of Economics and Business. 